\title{
Prevalence of depression in people with HIV and AIDS in Iran: A systematic review
}

\author{
Amin Doosti-Irani ${ }^{1}$, Hossein Moameri ${ }^{2}$, Hasan Ahmadi-Gharaei ${ }^{2}$, Kourosh Holakouie-Naieni ${ }^{2 *}$ \\ Received: 2 Feb 2017 \\ Published: 10 Dec 2017
}

\begin{abstract}
Background: Depression is the most common mental disorder in individuals with HIV and AIDS (PLWHA), and comorbidity with depression exacerbates the disease. Several studies have estimated the prevalence of depression in HIV and AIDS patients so far, but there is no consensus about the prevalence of depression among these patients. Thus, we aimed at estimating the overall prevalence of depression among Iranian PLWHA.

Methods: The international and national databases including Web of Science, Scopus, Medline, Science Direct, MagIran, Scientific Information Database (SID), IranMedex, and Medlib were searched until June 2016. The quality of included studies was assessed using Newcastle-Ottawa Scale.

Results: Out of 591 references, 9 cross-sectional studies met the eligibility criteria and were included in the review. The lowest and highest reported prevalence of depression among people with HIV was $22 \%$ (95\% CI: $(11,33))$ and $76 \%(95 \%$ CI: $(71,81))$, respectively. Prevalence of depression in people with HIV in the north, west, and south of Iran was 45\% (95\% CI: (23, 67)), 30\% (95\% CI: $(15,45))$, and $56 \%(95 \% \mathrm{CI}:(35,77))$, respectively. Prevalence of depression among addict and non-addict patients was $25 \%(95 \% \mathrm{CI}$ : $(21,30))$ and $58 \%(95 \% \mathrm{CI}:(40,77))$, respectively.

Conclusion: According to the results of this systematic review, the prevalence of depression is considerable among Iranian PLWHA. Prevalence in the southern regions of Iran is more than the western and northern regions of Iran. This evidence may be useful for Iranian health policymakers to design suitable preventive and therapeutic interventions in PLWHA to prevent and control depression among these people in Iran.
\end{abstract}

Keywords: Depression, HIV, Acquired Immunodeficiency Syndrome, Prevalence, Systematic Review

Copyright $\odot$ Iran University of Medical Sciences

Cite this article as: Doosti-Irani A, Moameri H, Ahmadi-Gharaei H, Holakouie-Naieni K. Prevalence of depression in people with HIV and AIDS in Iran: A systematic review. Med J Islam Repub Iran. 2017 (10 Dec);31:75. https://doi.org/10.14196/mjiri.31.75

\section{Introduction}

Nowadays, HIV/AIDS is a major public health concern worldwide. According to the World Health Organization (WHO), 36.7 million people live with HIV and AIDS and 1.1 million deaths have occurred due to AIDS worldwide in 2015 (1). Depression is the most common mental disorder among people with HIV and AIDS (PLWHA) (2), and comorbidity with depression exacerbates the prognosis of HIV and AIDS (3). The prevalence of depression in PLWHA is approximately 2 times of HIV-negative people (4). Among female HIV positive, the prevalence of de-

Corresponding author: Dr Kourosh Holakouie-Naieni, holakoik@hotmail.com

1. Department of Epidemiology, School of Public Health, Hamadan University of Medical Sciences, Hamadan, Iran.

2. Department of Epidemiology and biostatistics, School of Public Health, Tehran University of Medical Sciences, Tehran, Iran. pression is nearly 4 times of female HIV-negative people (5). The prevalence of depression among PLWHA varies from $5 \%$ to $79 \%$ around the world $(2,6-10)$. Depression has more major complications for PLWHA than the general population. These complications are an increase in mortality $(11)$, suicide $(8,10)$, and increase in drug abuse, sleep disorder, decrease in social function, and decrease in the number of CD4 in patients (12-14).

There are approximately 73000 individuals with HIV and AIDS In Iran (15), and the trend of the disease preva-

$\uparrow$ What is "already known" in this topic:

The prevalence of depression among Iranian PLWHA has been reported to be $53 \%$ to $85 \%$, however, there is no universal consensus about the prevalence of depression.

$\rightarrow$ What this article adds:

This study provides summary measures of the prevalence of depression among these people based on addiction status, geographic area, and the used questionnaires for the diagnosis of depression. The results revealed that prevalence of depression in patients who live in the south of Iran was more than other regions. 
lence is increasing (16). The quality of life and health of PLWHA are affected by depression and mental disorders (17). With an increase in the prevalence of HIV in Iran, depression can be a major problem for these patients, an additional burden for the health care system, and health care providers. Thus, estimating the overall prevalence of depression among PLWHA can be useful for the health policymakers to design health care services.

To date, several cross-sectional studies have estimated the prevalence of depression among these patients. According to the results of these studies, the prevalence of depression has been reported to be $53 \%$ to $85 \%(13,18$ 22 ), therefore, there is no universal consensus about the prevalence of depression among these patients in Iran. This systematic review aimed at estimating the overall prevalence of depression among Iranian patients with HIV and AIDS.

\section{Methods \\ Searching strategy}

The national and international scientific databases including scientific information database (SID), MagIran, IranMedex, Medlib, Medline, Web of science, Scopus, and SinceDirect were searched until June 2016. The following keywords were used in the search strategy: HIV, AIDS, depression, prevalence, incidence, and Iran. In addition, to obtain more studies, the reference lists of included studies were scanned, the authors of the selected studies were contacted, and the websites of the related conferences were searched to obtain the unpublished articles up to June 2016.

\section{Eligibility criteria for including the studies}

All cross-sectional studies that estimated the prevalence of depression among Iranian PLWHA using standardized questionnaires were included. There was no limitation in the time and language of the published papers.

\section{Data collection}

Two investigators (HM, HAG) were responsible for screening the titles and abstracts of the retrieved studies; and in the next step, the full text of the selected studies were reviewed according to the eligibility criteria. Any disagreement between the two authors was resolved by the judgment of the third author (ADI). The following variables were extracted from selected studies: first author, year of publication, the location of study conduction, sample size, the number of people with depression, mean age, gender, addiction status, and type of used questionnaire for detection of depression.

\section{Risk of bias assessment}

The Newcastle-Ottawa Scale (NOS), which has been adapted for cross-sectional studies, was used for assessment of bias risk of the included studies. The NOS has three 3 domains, which are as follow: selection, comparability, and outcome. Because we aimed at assessing the prevalence of depression, we used selection and outcome domains with the following items: (1) representativeness of the sample; (2) determining the sample size; (3) report- ing the non-respondents; (4) assessing the outcome, and (5) statistical tests $(23,24)$.

\section{Heterogeneity assessment and statistical analysis}

The statistical heterogeneity in the results of the included studies was assessed using chi-2 test and quantified by I2 (25). In addition, the between-study variance was estimated using the tau-square statistic (26). Meta-analysis was conducted to obtain a summary measure of prevalence of depression in PLWHA. The random effects model was used to report the results with $95 \%$ confidence interval (CI). The Metan Stata module (Stata 11, Stata Corp, College Station, TX, USA) was used for data analysis.

\section{Results}

In this systematic review, 591 cross-sectional studies were included, 483 from international databases, 77 from national databases, and 30 from the reference lists of the selected studies, and 1 through contacting the authors. Finally, after removing duplicated studies and checking the eligibility criteria, 9 cross-sectional studies (13, 18-22, 27-29) were included in the review (Fig. 1). These articles involved 1260 people with HIV and AIDS. The characteristics of the included studies are presented in Table 1. The risk of bias table is displayed in Table 2 .

\section{Heterogeneity test}

According to the results of chi-square test, the results of included studies were highly and significantly heterogeneous, $\mathrm{I} 2=97.1 \%(\mathrm{p}<0.001)$. Therefore, we could not combine the results of the studies. However, we reported the pooled estimate of the prevalence of depression based on the addiction status, geographical area, and type of used questionnaire.

\section{Estimate of prevalence}

The highest prevalence of depression among people with HIV (76\%, 95\% CI: $(71,81))$ had been reported by Amin Lari et al. in Shiraz (18), and the lowest prevalence $(22 \%, 95 \%$ CI: $(11,33))$ had been reported in Kermanshah (28). in another study in Kermanshah the prevalence was found to be $37 \%(95 \% \mathrm{CI}:(29,45))(29)$ (Table 1$)$.

We pooled the prevalence according to the addiction status, geographical regions of Iran, and the used questionnaire for assessing the depression among people with HIV and AIDS. However, there was considerable heterogeneity in the mentioned subgroups. However, there was no heterogeneity in the results of studies that involved addicted patients $(\mathrm{I} 2=0)$. Prevalence of depression among addicted and nonaddicted patients was $25.5 \%$ (95\% CI: $(20.7,30.2))$ and $58.3 \%$ (95\% CI: $(39.7,77.0))$, respectively. According to the pooled results of studies conducted in the north, west, and south regions of Iran, prevalence of depression was $44.7 \%$ (95\% CI: $(22.7,66.7)), 30.0 \%$ (95\% CI: $(15.2,44.7))$, and 56.0\% (95\% CI: $(35.3,76.7))$, respectively (Table 3$)$.

\section{Discussion}

According to the results of this systematic review, the prevalence of depression among people living with HIV 


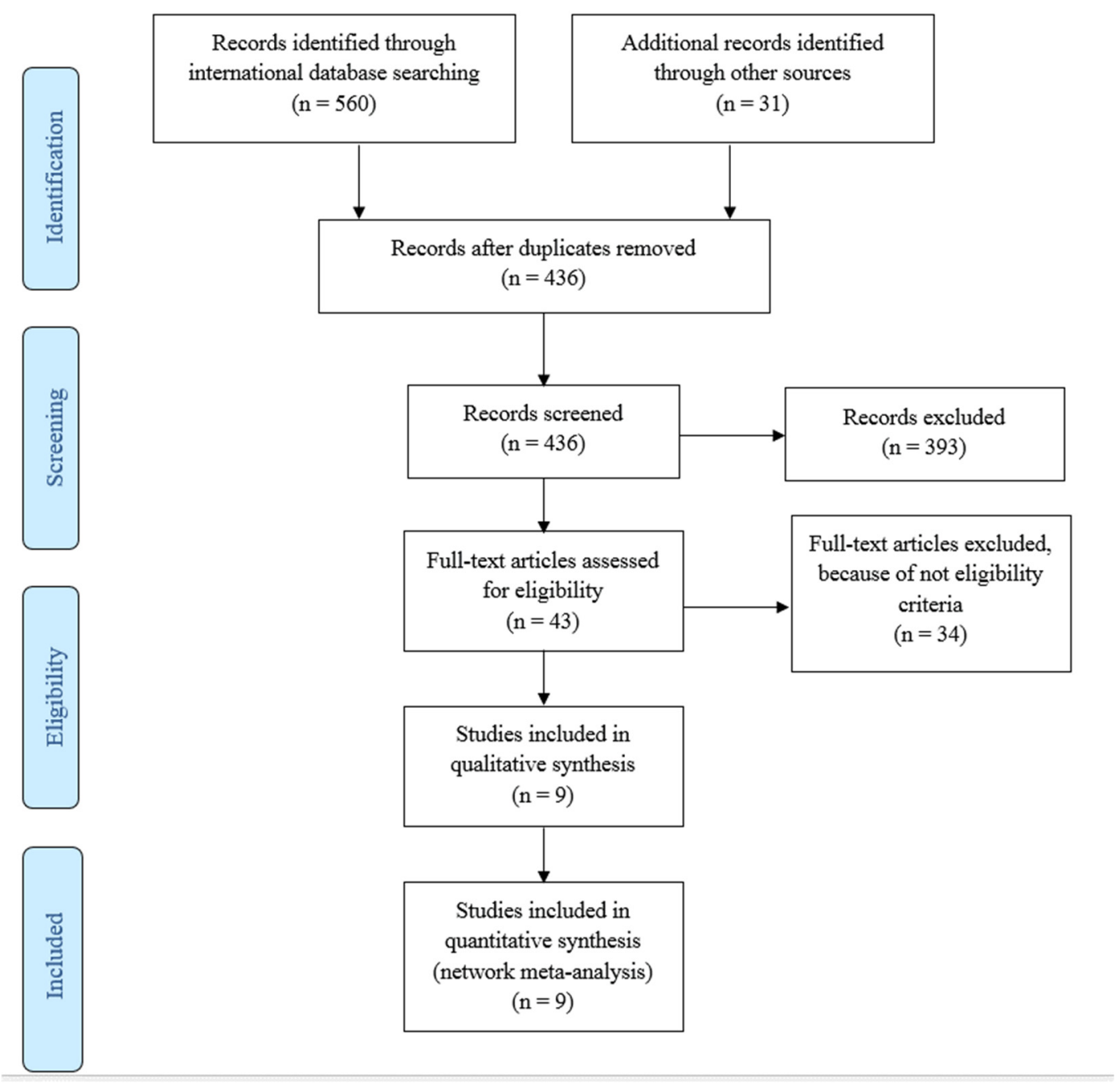

Fig. 1. A flow chart depicting the stages of retrieving articles and checking eligibility criteria for meta-analysis

varied from $22 \%$ to $76 \%$. The pooled prevalence of depression in the west of Iran (30\%) was lower than in the north $(45 \%)$ and south of Iran (56\%). In addition, the prevalence among people addicted to drugs $(25 \%)$ was lower than the nonaddicted patients $(58 \%)$. Overall, the prevalence of depression among people HIV and AIDS was considerable.

The prevalence of depression among people with HIV is more than the general population in Iran (30). Some factors were reported as reasons for more prevalence of de-

Table 1. Characteristics of the included studies in systematic review of the prevalence of depression among Iranian PLWHA

\begin{tabular}{|c|c|c|c|c|c|c|c|}
\hline Study & Province & Sex & Age & Sample size & Addiction & $\begin{array}{l}\text { Prevalence }(95 \% \\
\mathrm{CI})\end{array}$ & Questionnaire \\
\hline $\begin{array}{l}\text { Amini Lari et al., } \\
2010\end{array}$ & Shiraz & Male & 34.4 & 278 & No & $76 \%(71,81)$ & Beck Depression Inventory(BDI-II) \\
\hline $\begin{array}{l}\text { Moayedi et al., } \\
2012\end{array}$ & $\begin{array}{l}\text { Bandar } \\
\text { Abbas }\end{array}$ & Mix & 36 & 95 & Mixed & $73 \%(64,82)$ & $\begin{array}{l}\text { General Health Questionnaire -28 } \\
\text { (GHQ-28) }\end{array}$ \\
\hline $\begin{array}{l}\text { Rezaee et al., } \\
2011\end{array}$ & Tehran & Mix & 35.9 & 100 & No & $68 \%(59,77)$ & Beck Depression Inventory(BDI) \\
\hline Bagheripoor 2012 & Kerman & Mix & 39.6 & 83 & No & $48 \%(37,59)$ & $\begin{array}{l}\text { International Diagnostic Interview } \\
\text { (CIDI) }\end{array}$ \\
\hline $\begin{array}{l}\text { Emadi-Kouchaka } \\
2006\end{array}$ & Tehran & Mix & 37.9 & 199 & No & $41 \%(34,48)$ & Beck Depression Inventory(BDI-II) \\
\hline $\begin{array}{l}\text { Shakeri et al., } \\
2005\end{array}$ & Kermanshah & Mix & NR & 132 & Mixed & $37 \%(29,45)$ & NR \\
\hline Mobin et al., 2010 & Gilan & Mix & 33.4 & 270 & Yes & $26 \%(21,32)$ & Beck Depression Inventory(BDI) \\
\hline $\begin{array}{l}\text { Golestane et al., } \\
2012\end{array}$ & Shiraz & Mix & NR & 44 & Mixed & $25 \%(12,38)$ & MMPI-2 test \\
\hline Sayad et al., 2007 & Kermanshah & Mix & 34.3 & 59 & Yes & $22 \%(11,33)$ & $\begin{array}{l}\text { SCL-90-R questionnaire \& diagnostic } \\
\text { check list using criteria DSM- IV }\end{array}$ \\
\hline
\end{tabular}


Table 2. Results of risk assessment bias using modified Newcastle-Ottawa Scale

\begin{tabular}{|c|c|c|c|c|c|c|c|c|c|c|c|c|c|c|c|}
\hline \multicolumn{4}{|c|}{$\begin{array}{c}\text { Representativeness of the } \\
\text { sample }\end{array}$} & \multicolumn{2}{|c|}{$\begin{array}{l}\text { Determining the } \\
\text { sample size }\end{array}$} & \multicolumn{3}{|c|}{$\begin{array}{c}\text { Reporting the non- } \\
\text { respondents } \\
\end{array}$} & \multicolumn{4}{|c|}{ Assessing the outcome } & \multicolumn{2}{|c|}{ Statistical tests } & \\
\hline \multirow[t]{6}{*}{ 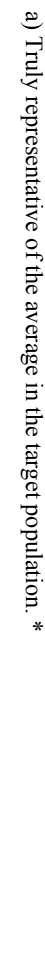 } & 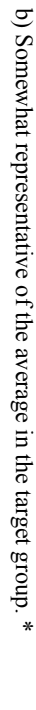 & $\begin{array}{l}0 \\
w \\
w \\
0 \\
0 \\
0 \\
0 \\
0 \\
0 \\
00 \\
0 \\
0 \\
0 \\
0 \\
D \\
0 \\
0 \\
0\end{array}$ & 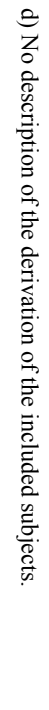 & 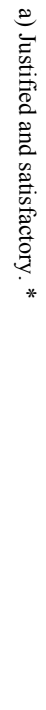 & 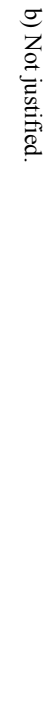 & 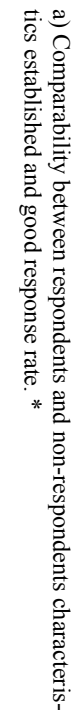 & 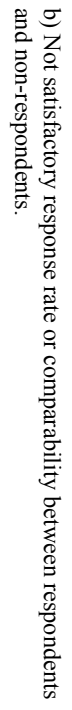 & 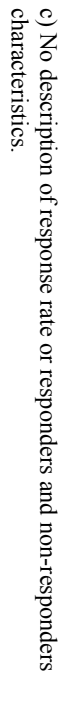 & 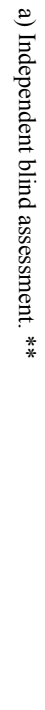 & 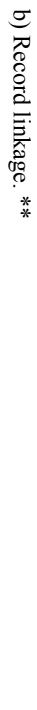 & 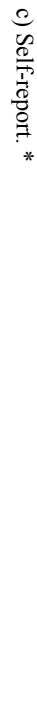 & $\begin{array}{l}a \\
z \\
z \\
o \\
0 \\
0 \\
0 \\
0 \\
0 \\
0 \\
0\end{array}$ & 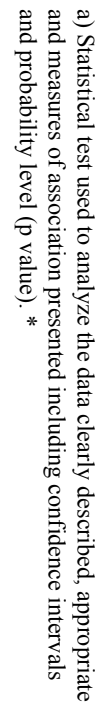 &  & $\begin{array}{l}\text { ద } \\
\delta \\
\sigma\end{array}$ \\
\hline & $*$ & & & $*$ & & & & & & $* *$ & & & $*$ & & 5 \\
\hline & * & & & & & & & & & ** & & & * & & 4 \\
\hline & & & & & & & & & & $* *$ & & & $*$ & & 3 \\
\hline & & & & $*$ & & $*$ & & & & $* *$ & & & $*$ & & 5 \\
\hline & & & & $*$ & & $*$ & & & & $* *$ & & & $*$ & & 5 \\
\hline & & & & & & & & & & & * & & & & 1 \\
\hline$*$ & & & & $*$ & & & & & & $* *$ & & & & & 4 \\
\hline & $*$ & & & & & & & & & ** & * & & & & 3 \\
\hline
\end{tabular}

Amini Lari 2010 Moayedi 2012

Rezaee 2011

Bagheripoor 2012

Emadi-Kouchaka

2006

Shakeri 2005

Mobin 2010

Golestane 2012

Sayad 2007

* Stars indicating the quality score of each study. The maximum score is 5 stars and minimum is zero.

Table 3. Subgroup analysis for prevalence of depression among PLWHA based on the geographical regions, addiction status, and type of the used questionnaire

\begin{tabular}{|c|c|c|c|c|}
\hline Variable & Prevalence & $95 \% \mathrm{CI}$ & $\mathrm{I} 2(\%)$ & p-value* \\
\hline \multicolumn{5}{|l|}{ Addiction status } \\
\hline Yes & 25.5 & $20.7,30.2$ & 0 & 0.479 \\
\hline No & 58.3 & $39.7,77.0$ & 96 & $<0.001$ \\
\hline Mixed & 45.1 & $17.5,72.8$ & 95.8 & $<0.001$ \\
\hline \multicolumn{5}{|l|}{ Geographic area } \\
\hline North & 44.7 & $22.7,66.7$ & 96.7 & $<0.001$ \\
\hline West & 30.0 & $15.2,44.7$ & 79.4 & $<0.027$ \\
\hline South & 56.0 & $35.3,76.7$ & 95.5 & $<0.001$ \\
\hline \multicolumn{5}{|l|}{ Used questionnaire } \\
\hline Beck Depression Inventory & 52.7 & $27.1,78.2$ & 98.5 & $<0.001$ \\
\hline Other questionnaires & 41.2 & $22.7,59.6$ & 94.1 & $<0.001$ \\
\hline
\end{tabular}

*p-value for heterogeneity test

pression in people with HIV than the general population, which are as follow: lack of social support, HIV-related stigma (31), lack of family support (32), and socioeconomic status (33).

In our study, prevalence of depression among addicted patients was lower than the nonaddicted HIV-infected patients. This finding is not in line with the other studies, which have shown that the prevalence of depression among addicted people is more than the nonaddict (3436). In this review, two studies have reported the prevalence of depression among addicted HIV-infected participants. Therefore, this finding cannot be representative of all addicted HIV-infected people in Iran.

In a national survey in France, the overall prevalence of depression among PLWHA was $21 \%$, and it was $32.8 \%$ and $55.7 \%$ among male and female injection drug users, respectively (37). Prevalence of depression among Iranian HIV-infected people was more than that of those in France. The reasons for higher prevalence in Iran may be due to social stigma and low social support for Iranian HIV-infected patients (38). However, prevalence among Iranian addicted patients was lower than that of the French. According to the results of a systematic review, prevalence of depression among people with HIV in low-, middle-, and high-income families was $31.8(95 \% \mathrm{CI}$ : 17.0, 51.5), 47.4 (95\% CI: $31.3,64.1)$, and 37.1 (95\% CI: $30.6,44.2)$, respectively (39). Results of our systematic review in Iran, as a middle-income country, were in the line with those of the mentioned systematic review.

According to the geographic regions of Iran, the higher prevalence was related to southern regions of Iran. On the other hand, there was an association between prevalence 
of depression among HIV-infected individuals and socioeconomic status (37). In addition, people with low income and low education level were at a higher risk of depression (40). The socioeconomic status of PLWHA in the southern regions may be lower than the northern region of Iran, so this may be the reason for higher prevalence of depression in the southern regions of Iran. However, more studies are needed to confirm this finding.

There was an association between depression and nonadherence to treatment among people living with HIV (41). Prevalence of depression among Iranian HIVinfected people is considerable, so the reason for nonadherence to treatment in HIV-infected people in Iran may be the high prevalence of depression. However, more studies, especially national studies, are needed to determine the prevalence of nonadherence to treatment in those HIV-infected people who are affected by depression, and association of depression, and nonadherence to treatment. In addition, conducting studies about depression and neurologic disorders of HIV-infected individuals and adherence to treatment are in priority for research in Iran (42).

There were some limitations in this review. First, some included studies had a low quality; second, a low sample size of some included studies might have increased the selection bias; and subsequently, the results might have not been representative of all Iranian HIV-infected people; third, the tools for assessing depression in the included studies were not the same, Beck Depression Inventory, SCL-90-R questionnaire, MMPI-2 test, General Health Questionnaire -28 (GHQ-28), and International Diagnostic Interview (CIDI) had been used as tools for diagnosis of depression among PLWHA. This might have increased the risk of information bias and might have been a reason for high heterogeneity in the results of the included studies. In addition, the low number of included studies was another limitation in this review. Finally, we recommend conducting further studies to assess mental disorders, especially depression, among Iranian PLWHA using standardized tools.

\section{Conclusion}

Results of this systematic review revealed that the prevalence of depression among Iranian people with HIV is considerable. Prevalence in the southern regions of Iran was more than the western and northern regions of Iran. This evidence may be useful for Iranian health policymakers to design suitable preventive and therapeutic interventions for those with HIV to prevent and control depression among these people in Iran.

\section{Acknowledgments}

We would like to thank Dr. Zahra Cheraghi for technical support of this study. In addition, we would like to thank the Department of Epidemiology and Biostatistics of Tehran University of Medical Sciences for technical support of this study.

\section{Conflict of Interests}

The authors declare that they have no competing interests.

\section{References}

1. WHO. HIV/AIDS (updated November 2016; cited 12 Desember 2016. Available from: http://www.who.int/mediacentre/factsheets/ fs $360 /$ en/.

2. Olley BO, Seedat S, Stein DJ. Persistence of psychiatric disorders in a cohort of HIV/AIDS patients in South Africa: a 6-month follow-up study. J Psychosom Res. 2006;61(4):479-84.

3. Dejman M, Ardakani HM, Malekafzali B, Moradi G, Gouya MM, Shushtari ZJ, et al. Psychological, social, and familial problems of people living with HIV/AIDS in Iran: A qualitative study. Int J Prev Med. 2015;6:126.

4. Ciesla JA, Roberts JE. Meta-analysis of the relationship between HIV infection and risk for depressive disorders. Am J Psychiatry. 2001;158(5):725-30.

5. Morrison MF, Petitto JM, Have TT, Gettes DR, Chiappini MS, Weber AL, et al. Depressive and anxiety disorders in women with HIV infection. Am J Psychiatry. 2002;159(5):789-96.

6. Bing EG, Burnam MA, Longshore D, Fleishman JA, Sherbourne CD, London AS, et al. Psychiatric disorders and drug use among human immunodeficiency virus-infected adults in the United States. Arch Gen Psychiatry. 2001;58(8):721-8.

7. Charles B, Jeyaseelan L, Pandian AK, Sam AE, Thenmozhi M, Jayaseelan V. Association between stigma, depression and quality of life of people living with HIV/AIDS (PLHA) in South India-a community based cross sectional study. BMC Public Health. 2012;12:463.

8. Jin H, Atkinson JH, Yu X, Heaton RK, Shi C, Marcotte TP, et al. Depression and suicidality in HIV/AIDS in China. J Affect Disord. 2006;94(1):269-75.

9. Mwesiga EK, Mugenyi L, Nakasujja N, Moore S, Kaddumukasa M, Sajatovic M. Depression with pain co morbidity effect on quality of life among HIV positive patients in Uganda: a cross sectional study. Health Qual Life Outcomes. 2015;13:206.

10. Obadeji A, O Ogunlesi A, O Adebowale T. Prevalence and predictors of depression in people living with HIV/AIDS attending an outpatient clinic in Nigeria. Iran $\mathrm{J}$ Psychiatry Behav Sci. 2014;8(1):26-31.

11. Cook JA, Grey D, Burke J, Cohen MH, Gurtman AC, Richardson $\mathrm{JL}$, et al. Depressive symptoms and AIDS-related mortality among a multisite cohort of HIV-positive women. Am J Public Health. 2004;94(7):1133-40.

12. Junqueira P, Bellucci S, Rossini S, Reimão R. Women living with HIV/AIDS: sleep impairment, anxiety and depression symptoms. Arq Neuropsiquiatr. 2008;66(4):817-20.

13. Moayedi F, Hormozi SJ, Tahamtan I. Mental Health Status of Patients With HIV/AIDS in the South of Iran. Health Scope. 2015;4(2):e25796.

14. Tucker JS, Burnam MA, Sherbourne CD, Kung F-Y, Gifford AL. Substance use and mental health correlates of nonadherence to antiretroviral medications in a sample of patients with human immunodeficiency virus infection. Am J Med. 2003;114(7):573-80.

15. UNAIDS. HIV and AIDS estimates (2015) (updated March 201512 Desember, 2016). Available from: http://www.unaids.org/en/regionscountries/countries/islamicrepublico firan.

16. Haghdoost AA, Mostafavi E, Mirzazadeh A, Navadeh S, Feizzadeh A, Fahimfar N, et al. Modelling of HIV/AIDS in Iran up to 2014. J AIDS HIV Res. 2011;3(12):231-9.

17. Tate D, Paul RH, Flanigan TP, Tashima K, Nash J, Adair C, et al. The impact of apathy and depression on quality of life in patients infected with HIV. AIDS Patient Care STDS. 2003;17(3):115-20.

18. Amini Lari M, Faramarzi H, Shams M, Marzban M, Joulaei H. Sexual dysfunction, depression and quality of life in patients with HIV infection. Iran J Psychiatry Behav Sci. 2013;7(1):61-8.

19. Bagheripoor H, Karimaddini ZK, Boshrabadi AP, Anar ARS, Ghanad MS, Bidaki R, et al. Frequency of Major Psychiatric Disorders in Patients with HIV in Health Care Centers of Rafsanjan and Kerman in 2012. GMJ. 2013;2(3):95-9.

20. Emadi Khochak H, Noorifard M, Kashi Amir H, Arbabi M, Kheirandish P, Moradmand Badie B, et al. Evaluation of depression in HIV/AIDS patients refering to behavioral counselling center of Imam Khomeini Hospital. Acta Med Iran. 2009;47(3):193-6.

21. Amini Lari M, Parsa N, Marzban M, Shams M, Faramarzi H. Depression, testosterone concentration, sexual dysfunction and 
methadone use among men with hypogonadism and HIV infection. AIDS Behav. 2012;16(8):2236-43.

22. Rezaee H, Khalili H, Hatamkhani S, Dashti-Khavidaki S, Khazaeipour Z. Frequency of Depression and its Correlation with Serum Carnitine Level in HIV/AIDS Patients. Curr HIV Res. 2013;11(3):226-30.

23. Stang A. Critical evaluation of the Newcastle-Ottawa scale for the assessment of the quality of nonrandomized studies in meta-analyses. Eur J Epidemiol. 2010;25(9):603-5.

24. Elyasi M, Abreu LG, Badri P, Saltaji H, Flores-Mir C, Amin M. Impact of Sense of Coherence on Oral Health Behaviors: A Systematic Review. PLoS One. 2015;10(8):e0133918.

25. Higgins JP, Thompson SG, Deeks JJ, Altman DG. Measuring inconsistency in meta-analyses. BMJ. 2003;327(7414):557-60.

26. Higgins JP, Green S. Cochrane Handbook for Systematic Reviews of Interventions Version 5.1.0 (updated March 2011): The Cochrane Collaboration; 2011. Available from: www.handbook.cochrane.org.

27. Mobaein A. Compression of depression frequency in HIV positive and HIV negative among IV drug abusers. Journal of Guilan University of Medical Sciences. 2011;19(76):71-6 (Persian).

28. Sayad B, Shakeri J, Hoseini M, Janbakhsh A, Aminijavid F, Omidniakan Z. Correlation of psychiatric disorders with CD4 counts in HIV/AIDS patients in Sina hospital, Kermanshah. Research in Medicine. 2007;31(3):247-54 (Persian).

29. Shakeri J, Parvizifard AA, Aminzadeh S. Mental status of HIV positive patients referred to Kermanshah health care center. J Kermanshah Univ Med Sci. 2006;10(1):1-8.

30. Montazeri A, Mousavi SJ, Omidvari S, Tavousi M, Hashemi A, Rostami T. Depression in Iran: a systematic review of the literature (2000-2010). Payesh. 2013;12(6):567-94 (Persian).

31. Vyavaharkar M, Moneyham L, Corwin S, Saunders R, Annang L, Tavakoli A. Relationships between stigma, social support, and depression in HIV-infected African American women living in the rural Southeastern United States. The Journal of the Association of Nurses in AIDS Care : JANAC. 2010;21(2):144-52.

32. Shrestha S, Poudel KC, Poudel-Tandukar K, Kobayashi J, Pandey $\mathrm{BD}$, Yasuoka J, et al. Perceived family support and depression among people living with HIV/AIDS in the Kathmandu Valley, Nepal. J Int Assoc Provid AIDS Care. 2014;13(3):214-22.

33. Unnikrishnan B, Jagannath V, Ramapuram JT, Achappa B, Madi D. Study of depression and its associated factors among women living with HIV/AIDS in Coastal South India. ISRN AIDS. 2012;2012:684972.

34. Conner KR, Pinquart M, Duberstein PR. Meta-analysis of depression and substance use and impairment among intravenous drug users (IDUs). Addiction. 2008;103(4):524-34.

35. Conner KR, Pinquart M, Holbrook AP. Meta-analysis of depression and substance use and impairment among cocaine users. Drug Alcohol Depend. 2008;98(1):13-23.

36. Ross LE, Dennis C-L. The prevalence of postpartum depression among women with substance use, an abuse history, or chronic illness: a systematic review. J Womens Health (Larchmt). 2009; $18(4): 475-86$.

37. Feuillet P, Lert F, Tron L, Aubriere C, Spire B, Dray-Spira R. Prevalence of and factors associated with depression among people living with HIV in France. HIV Med. 2016.

38. Forouzan AS, Jorjoran Shushtari Z, Sajjadi H, Salimi Y, Dejman M. Social Support Network among People Living with HIV/AIDS in Iran. AIDS Res Treat. 2013;2013:715381.

39. Uthman OA, Magidson JF, Safren SA, Nachega JB. Depression and Adherence to Antiretroviral Therapy in Low-, Middle- and HighIncome Countries: A Systematic Review and Meta-Analysis. Curr HIV/AIDS Rep. 2014;11(3):291-307.

40. Bhatia M, Munjal S. Prevalence of depression in People Living with HIV/AIDS undergoing ART and factors associated with it. J Clin Diagn Res. 2014;8(10):WC01-WC4.

41. Gonzalez JS, Batchelder AW, Psaros C, Safren SA. Depression and HIV/AIDS treatment nonadherence: a review and meta-analysis. J Acquir Immune Defic Syndr. 2011;58(2):181-7.

42. Doosti-Irani A, Holakouie-Naieni K. Determination the Research Priorities in the Field of HIV/AIDS in Iran: A Systematic Review Article. Iranian journal of public health. 2016;45(9):1149-58. 